|| Print ISSN: 2589-7837 || Online ISSN: 2581-3935 ||

International Journal of Medical Science and Diagnosis Research (IJMSDR)

Available Online at www.ijmsdr.com

NLM (National Library of Medicine ID: 101738824)

Original Research Article

Volume 5, Issue 3; April:2021; Page No. 22-26

\title{
ACUTE HEMODYNAMIC RESPONSE TO ACAPELLA FOLLOWING ABDOMINAL
} SURGERY

A. Brahmini ${ }^{1}$, A. Sankarganesh ${ }^{2}$

${ }^{1}$ BPT Intern SRM College of Physiotherapy, SRM University, Kattankulathur

${ }^{2}$ Assistant Professor, SRM College of Physiotherapy, SRM University, Kattankulathur

Conflicts of Interest: Nil

Corresponding author: A. Sankarganesh

DOI: https://doi.org/10.32553/ijmsdr.v5i4.785

\section{Abstract:}

Background: The effectiveness of standard chest physiotherapy (CPT) has been confirmed by many studies. Airway CPT is considered the base of physiotherapy and is characterized as "gold standard" of physiotherapy. Chest physiotherapy is a routinely used therapy to prevent post-operative pulmonary complications after abdominal surgery. There are different types of devices used to deliver PEP but one of the most commonly used is Acapella. It has more stable wave form and a wider range of PEP at low air flow.

Objective: To find out the effect of hemodynamic response to acapella in abdominal surgery patients.

Methodology: Study design is Quasi experimental, study type is pre-test - post-test type, and sampling method is convenient sampling, sample size is 36, study duration of 4 weeks, study setting in SRM medical college hospital research centre, Kattankulathur. Procedure: Acapella device was selected depending upon the patient's ability to maintain an expiratory flow of 15 litres per minute. Patients were explained with complete procedure prior to examination. Mouthpiece was used during exhalation. Patients were asked to breath from diaphragm taking deep breath. Hold breath for 2-3 seconds. They were asked to Perform 10-20 PEP breaths and then asked to remove the mouthpiece and perform 2-3 'huffs' coughs to raise secretions as needed. This was repeated 3- 4 times. Results: There is no significant improvement by using acapella in systolic blood pressure, diastolic blood pressure, heart rate, respiratory rate, arterial oxygen saturation rate.

Conclusion: This study concludes that there was an increase in hemodynamic variables during the usage of acapella which return back to normal values in post 30 minutes of training. Thus, acapella is safe, effective to use for airway clearance.

Key words: abdominal surgery, acapella, airway clearance, hemodynamics.

\section{Introduction:}

Abdominal surgery changes postoperative pulmonary function, by loss of respiratory volumes such as total lung capacity (TLC), Vital Capacity and Residual Volume. Vital capacity (VC) is the amount of air expelled out after the inspiration and tidal volume (TV) is the maximal level of air displaced inward or outward of lung during normal breathing.

The number of subjects who have gone through abdominal surgery have less vital capacity (VC) in post- operative period, this includes Ventilation/perfusion (v/q) ratio that contributes to development of hypoxemia. ${ }^{1} 4$ million abdominal surgeries are done per annum. ${ }^{2}$ Patients done with abdominal surgery are at increased risk for pulmonary complications postoperatively. $^{3}$

The main reason to get complaints after abdominal surgery is denial of expulsion of secretions due to pain. Failure to clean mucosal substances which are formed in lungs can end up on complications like atelectasis, pneumonia, and increased mortality . ${ }^{7}$

Respiratory exercises during post-operative period in Intensive Care Unit has been proved to elevate the strength of inspiratory and expiratory 
muscles, oxygen capacity, coughing and huffing mechanism, chest wall re-expansion and ventilation, also reduce the respiratory overload and avoid postoperative lung complications (Kisner and Colby, 2002). ${ }^{8}$

In pulmonary function a major decline is observed on first post-operative period of the abdominal surgery. This can decrease inspiratory and vital capacity and result in inhibition of the lung function and it leads to atelectasis (Atelectasis is the collapse or closure of a lung resulting in reduced gas exchange). It can affect one part or full of the airway passage. It is usually occurs in one direction. It is a condition where the alveoli becomes empty down, at the end it becomes lung consolidation, the situation in which lung is filled with liquid. It is known as a collapsed lung. Reduced diaphragmatic movement and respiratory insufficiency is quite common in this condition. (Dronkers et al., 2008). ${ }^{8}$

The Acapella has the benefits of both pressure of positive expiration and vibrations which is useful in secretions mobilisation and can be followed in different position. Based on patient comfort it can be used in sitting, standing, lying. Half lying may be more comfortable to avoid atelectasis and promotes airway opening in patient with lung complications and heavy secretion problems. ${ }^{9}$ It is used to maintain airway hygiene and lung reexpansion ${ }^{6}$. There are many number of studies that includes oscillations and vibrations which will improve the mucosal airway clearance and further maintain proper lung function in various conditions. Previously, no research has determined the effect of vibratory positive expiratory pressure using the Acapella device in subjects undergoing abdominal surgeries.

The Acapella contains a counterbalanced plug and metal plate inside which is clenched to a handle, and a magnet. Oscillations are divided and formed by a magnet through the plug as it includes passage of air through this device. ${ }^{4}$ The device will be available in different colours like blue; this is for patients who cannot maintain their expiratory flow above15.1 litres/min for 1 to 3 seconds, or green, for patients who can maintain an expiratory flow equal to or above 15.1 litres/min for at least 3 seconds . 5, 10

The analysis of blood flow is called haemodynamic. Circulatory system is maintained and adapted by homeostasis. Homeostasis is a state of balance in the body, preserved and supported by self-regulatory process. Hemodynamics response regulates faster delivery to blood in order to maintain active nerve tissues. It is a response constantly monitored and adjusted, adapted according to body conditions. Blood supplies oxygen, carbon dioxide, nutrients, hormones, metabolic waste whole body to maintain $\mathrm{pH}$, cell level metabolism, osmotic pressure, and temperature of body. In abdominal surgery patients there will be a compromise of hemodynamic response because of pain, the patient body homeostasis also change.

\section{Procedure:}

This was Quasi Experimental Study design. A total of 36 subjects post abdominal surgery were selected from the hospital based upon inclusion and exclusion criteria. Informed consent was taken with knowledge of the subjects.

Acapella device was used depending on the patient's ability to maintain the expiratory flow of 15 litres per minute (LPM). All patients were able to maintain expiratory flow $>15$ LPM litres /minute therefore, green Acapella was used for the subjects. At beginning stage the device duration and the dial was adjusted and moved counterclockwise to reduce the duration setting, then duration increased clockwise. The resistance range was selected to produce I: E ratio of 1:3 to 1:4. Patients were informed to do the explained procedure before the examination. Patients were allowed to sit in relax position and place mouthpiece in mouth and maintain a tight seal on at the beginning.

Before starting the procedure patients were asked to insert and hold the mouthpiece in to the mouth. Patients were said to breathe from diaphragm inhaling more amount of air than the normal breathing. Ask patient to hold the breath for 2 to 3 seconds. Patients were instructed to exhale 
normally by themselves not forcefully, through the device; exhalation should be there for about approximately 3 to 4 times more than inhalation. Subjects were said to do 10 to 20 positive expiratory pressure (PEP) breaths and then said to take off the mouthpiece and perform 2 to 3 'huffs' coughs to improve secretions. This procedure was done 3 to 4 times. Hemodynamic variables were taken pre-test before using Acapella, during test at the time using Acapella, post-test immediately after using Acapella and 30 minutes after using acapella.

Results:

Table 1:

\begin{tabular}{|c|c|c|c|c|c|c|c|c|}
\hline Vitals & \multicolumn{4}{|l|}{ Mean } & \multicolumn{3}{|c|}{ Standard deviation } & \\
\hline & $\begin{array}{l}\text { Before } \\
\text { using } \\
\text { acapella }\end{array}$ & $\begin{array}{l}\text { During } \\
\text { acapella }\end{array}$ & $\begin{array}{l}\text { Immediately } \\
\text { After using } \\
\text { acapella }\end{array}$ & $\begin{array}{l}\text { After } \\
30 \\
\text { mins }\end{array}$ & $\begin{array}{l}\text { Before } \\
\text { using } \\
\text { acapella }\end{array}$ & $\begin{array}{l}\text { During } \\
\text { acapella }\end{array}$ & $\begin{array}{l}\text { Immediately } \\
\text { After using } \\
\text { acapella }\end{array}$ & $\begin{array}{l}\text { After } \\
30 \\
\text { mins }\end{array}$ \\
\hline HR & 86.52 & 88.33 & 86.75 & 86.75 & 16.32 & 16.32 & 16.63 & 16.63 \\
\hline SBP & 116.86 & 118.88 & 117.33 & 117.58 & 15.626 & 14.914 & 15.182 & 14.61 \\
\hline DBP & 72.83 & 73.75 & 73.38 & 72.86 & 11.18 & 11.28 & 11.15 & 10.61 \\
\hline $\mathbf{R R}$ & 15.88 & 16.94 & 16.33 & 16.00 & 3.91 & 3.71 & 3.83 & 3.84 \\
\hline SPO2 & 99.88 & 100 & 99.75 & 99.86 & 6.04 & 6.23 & 6.17 & 6.043 \\
\hline
\end{tabular}

Mean value of Heart rate, Blood pressure, Respiratory rate, SPO2 before using acapella, during acapella, immediately after using acapella, 30 minutes after using acapella among post abdominal surgical patients.

\section{Discussion:}

The study was aimed to find out the acute hemodynamic response to acapella in abdominal surgery patient. This study was conducted on thirty six patients who had undergone abdominal surgery and their ages ranged from 40 to 80 years. Effect of Acapella was examined through this study by measuring acute hemodynamics before using acapella, during acapella, immediately after using and 30minutes after using acapella program.

The respiratory system is important in human body for gases exchange and it is divided into following two parts one is conducting and gas exchanging part. The conducting airways are subdivided anatomically into the nose and mouth, pharynx, larynx, trachea and bronchi and branches down into the level of respiratory bronchioles. There is corresponding alveoli which represents gas exchanging part of lungs from the division of respiratory bronchioles.
This will help in normal expiration and facilitates proper contraction of diaphragm. The lower ribs are attached with the abdominal muscles and this helps in contraction of these muscles and the muscles reduces the rib cage size to assist expiration function of these muscles which raises the intra-abdominal pressure.

Increased activation of the abdominal muscles later decreases lung volume and the diaphragm gets lengthen during exercise. Therefore the abdominal muscles has an important role in both inspiration and expiration .when there is incision in the abdomen it leads to pain minimising the use of muscles for respiration the normal active breathing gets decreased which leads to further complications like increased sputum collection in the lungs. So it is important to clear the secretion formation regularly for normal function. One of them is Acapella training.

The effect of Acapella on hemodynamic performance was examined in a group of subjects who undergone for abdominal surgery. The result include that who underwent for abdominal surgery there is minimal change in heart rate , systolic blood pressure, diastolic blood pressure, arterial saturation rate for oxygen while 
continuing this procedure, immediately after using and 30 minutes after procedure. ${ }^{11}$

Heart rate increases during using acapella and falls backs to normal in immediate and 30 minutes after acapella usage .The increase in heart rate is due to the changes that take place in intra-abdominal pressure while blowing in to acapella and this explains the immediate return of heart rate to normal after the acapella training.

Systolic and Diastolic Blood Pressure shows a minimal increase in Blood pressure during acapella training which is due to the change in intrathoracic pressure which falls down to normal level immediately after the acapella training and it sustains for about 30 minutes.

Fozia, 2013 concluded that Acapella could not demonstrate any change in these hemodynamic variables.

The present study demonstrated an improvement in SPO2 and respiratory rate after using Acapella. This result is in accordance with the studies of Darbee et al., in $\mathbf{2 0 0 5}$ who stated that high frequency chest wall oscillation and low positive expiratory pressure breathing demonstrated improvement in ventilation distribution, gas mixing and increase in SPO2.

This results goes in hand with O'Sullivan et al., (2013) who stated that the device for airway oscillation, such as the flutter or Acapella changes the airflow during exhalation throughout the airways. During active expiration from the acapella, the pressure causes an intermittent backward air that clears the mucosal secretions. The repeated procedure is to exhale 10 or so breaths from the acapella, continued by huge amount of exhalation through the device and needs a huff and cough to clear sputum secretions. This same procedure is repeated to clear secretions are cleared from the lungs. An airway oscillation device has shown to help in the clear of mucosal secretions from airways.

Hence this present study shows that there is minimal changes in hemodynamics may be due to some underlying pathological changes that occurred during or after the surgery. It can be improved by interventional methods. Therefore acapella is safe to use and the best effect of it was an increase in spo2 which is very essential for improving the Quality of life of post-surgical patients.

\section{Conclusion}

This study concludes that use of acapella device in post abdominal surgery shows minimal alteration in the hemodynamic variables, in addition to removal of bronchial secretions in patients undergoing abdominal surgery. Thus acapella may be safe and effective in post abdominal surgery conditions..

\section{Reference:}

1. Allam, nesma morgan abd el-aziz. Effect of Combination of Acapella Device and Breathing Exercises on Treatment of Pulmonary Complications After Upper Abdominal Surgeries. Diss. Cairo University, 2016.

2. Lawrence, Valerie A., et al. "Incidence and hospital stay for cardiac and pulmonary complications after abdominal surgery." Journal of general internal medicine 10.12 (1995): 671-678.

3. Devices such as the acapella may facilitate independent airway clinical surgeries Kathy stiller. Physiotherapy in intensive care: towards in evidence-based practice.chest.2000; $118: 18$

4. Al surgery, a systematic review Patrick pasquina; martin r. Trame`r, md, dphil; jeanmax granier; and Bernhard walder 2006.

5. Brooks-Brunn, Jo Ann. "Postoperative atelectasis and pneumonia." Heart \& Lung: The Journal of Acute and Critical Care 24.2 (1995): 94-115.

6. Patterson, J. E., et al. "Acapella ${ }^{\circledR}$ versus usual airway clearance 'during acute exacerbation in bronchiectasis: a randomized crossover trial." Chronic Respiratory Disease 4.2 (2007): 67-74.

7. Cho, Y. J., et al. "A randomised controlled trial comparing incentive spirometry with the Acapella ${ }^{\circledR}$ device for physiotherapy after 
thoracoscopic lung resection surgery." Anaesthesia 69.8 (2014): 891-898.

8. Owings, Maria F., and Lola Jean Kozak. "Ambulatory and inpatient procedures in the United States, 1996." Vital and health statistics. Series 13, Data from the National Health Survey 139 (1998): 1-119.

9. Moiz, Jamal Ali, Divya M. Shama, and M. Ejaz Hussain. "Acute Hemodynamic Response to Acapella in Phase 1 Cardiac
Rehabilitation Following Coronary Artery Bypass Graft Surgery." Physiotherapy and Occupational Therapy Journal 6.2 (2013): 65.

10. Darbee, Joan C., Jamshed F. Kanga, and Patricia J. Ohtake. "Physiologic evidence for high-frequency chest wall oscillation and positive expiratory pressure breathing in hospitalized subjects with cystic fibrosis." Physical therapy 85.12 (2005): 1278-1289. 